\title{
Re: Assisted Vaginal Birth: Green-top Guideline No. 26
}

\author{
Pauline McDonagh Hull ${ }^{1}$, Kim Thomas ${ }^{2}$, Elizabeth Skinner ${ }^{3}$, Amy Dawes ${ }^{4}$, and Penny \\ Christensen $^{5}$ \\ ${ }^{1}$ University of Calgary Department of Community Health Sciences \\ ${ }^{2}$ Birth Trauma Organisation \\ ${ }^{3}$ The University of Sydney \\ ${ }^{4}$ Australasian Birth Trauma Association \\ ${ }^{5}$ Birth Trauma Canada
}

May 12, 2020

Letter to the Editor, BJOG Exchange

Re: Assisted Vaginal Birth: Green-top Guideline No. 26

[Authors' title] Montgomery is missing from RCOG's Assisted Vaginal Birth guideline

Just weeks following the fifth anniversary of the landmark Montgomery v Lanarkshire Health Board Supreme Court judgment, the Royal College of Obstetricians and Gynaecologists (RCOG) has delivered the fourth edition of its Green-top guideline on forceps and vacuum assisted births ${ }^{1}$. The irony of this is not lost on those who expected real change following last year's peer review consultation (19 physicians and 6 maternity care organisations responded, including the first two signatories of this letter). The guideline opens with a fundamental question: Can assisted vaginal birth be avoided? The answers RCOG provides are solely in the context of labour (evidence on continuous support, epidural analgesia, positions adopted, delayed pushing), but a legal interpretation of Montgomery advises birth is "a situation that allows for significant advance planning and accordingly plans must be made." ${ }^{2}$ The guideline concurs: women "should be informed about assisted vaginal birth in the antenatal period, especially during their first pregnancy [and] in advance of labour". Nevertheless, while "lower rates in midwifery-led care settings" is included, "lower rates with planned caesarean' is not, and there is no direct equivalent Green-top for this birth mode. The Montgomery judgment on consent specifically states that doctors are "under a duty to take reasonable care to ensure that the patient is aware of any material risks involved in any recommended treatment, and of any reasonable alternative or variant treatments." It also emphasises that in any pregnancy, the "principal choice is between vaginal delivery and caesarean section." RCOG may argue that referencing the "alternative choice of a caesarean section late in the second stage of labour" sufficiently addresses these points. However, a Queen's Counsel who was involved in the Montgomery case reminds doctors that the mother "was not advised that an alternative to vaginal birth (i.e. caesarean section) was an option available to her... and there was an increased risk... should vaginal birth be attempted." ${ }^{2}$ He warns, "Where the patient asks a question, it must be answered honestly and fully", which suggests that planned caesarean birth omission from this Green-top could have serious legal consequences, and there is every chance the Montgomery case could reoccur.

Despite aiming "to provide evidence-based recommendations", RCOG does not include pelvic organ prolapse as an adverse outcome. Instead, it says women who "achieve an assisted vaginal birth rather than have a caesarean birth... are far more likely to have an uncomplicated vaginal birth in subsequent pregnancies", and that "much of the pelvic floor morbidity reported... may not be causally related to the procedure." Furthermore, the stated aim of RCOG's clinical Green-tops is to identify "good practice and desired outcomes", which will be "used globally." ${ }^{4}$ This is relevant because many countries define this as low caesarean 
birth rates. In the UK, the National Institute for Health and Care Excellence (NICE) does not advocate targets, and recommends support for prophylactic caesarean birth requests. ${ }^{3}$ Yet decades of promoting vaginal birth rather than informed choice has obstructed autonomy and contributed substantially to rising litigation costs. ${ }^{5}$ The truth is, the NHS simply cannot afford to keep repeating the same communication and consent mistakes, and in our view, this NICE accredited Green-top guideline clearly demonstrates that lessons from Montgomery have still not been learned.

Pauline M Hull, Founder, Caesarean Birth

Kim Thomas, CEO, Birth Trauma Organisation

Dr. Elizabeth Skinner, Faculty of Medicine, University of Sydney

Amy Dawes, Co-founder and CEO, Australasian Birth Trauma Association

Penny Christensen, Executive Director, Birth Trauma Canada

References

1. Murphy DJ, Strachan BK, Bahl R, on behalf of the Royal College of Obstetricians Gynaecologists.

Assisted Vaginal Birth. BJOG 2020; https://doi.org/10.1111/1471-0528.16092

2. Smith, A. (2017). Montgomery and implications for clinical practice. BJOG: An International Journal of Obstetrics and Gynaecology, 124 (8), 1148-1151.

3. National Institute for Health and Care Excellence. Caesarean section (update). CG132. 2011. http://guidance.nice.org.uk/CG132. 4. Royal College of Obstetricians and Gynaecologists. Developing a Green-top Guideline. London: RCOG; 2020. 5. West, J., Taylor, M., \& Magro, M. (2019). The true relative financial costs of Planned Caesarean Section (PCS) versus Planned Vaginal Birth (PVB) in England taking into account litigation and compensation for harm. F1000Research, 8 . doi.org/10.7490/f1000research.1.Disclosure of interests

Pauline M Hull is co-author of Choosing Cesarean, A Natural Birth Plan, and editor of caesareanbirth.org 